\title{
Erratum to: Canard Cycles of Finite Codimension with Two Breaking Parameters
}

\author{
Lilia Mahmoudi • Robert Roussarie
}

Published online: 31 May 2014

(C) Springer Basel 2014

Erratum to: Qual. Theory Dyn. Syst. (2012) 11:167-198 DOI 10.1007/s12346-011-0061-x

In the original publication of the article, the first author's name was incorrect. The correct name is Lilia Mahmoudi and not Lylia Mamouhdi.

The online version of the original article can be found under doi:10.1007/s12346-011-0061-x.

\section{Mahmoudi}

Laboratoire de mathématiques appliquées, Université Badji-Mokhtar, Annaba, Algeria

e-mail: lilia23mahmoudi@hotmail.fr

R. Roussarie $(\varangle)$

Institut de Mathématique de Bourgogne, U.M.R. 5584 du C.N.R.S.,

Université de Bourgogne, 21078 Dijon Cedex, France

e-mail: roussari@u-bourgogne.fr 